\title{
EDITORIAL
}

\section{Interstitial lung disease: are we missing formes frustes of connective tissue disease?}

\author{
V. Cottin
}

$\mathbf{P}$ atients with connective tissue disease (CTD) may encompass a variety of respiratory manifestations, including: pleural disease; pulmonary hypertension; bronchial or bronchiolar disease; interstitial pneumonia; restrictive lung disease secondary to musculo-skeletal changes; and iatrogenic drug-induced lung disease. Patients also have an increased risk of opportunistic infections, often favoured by corticosteroids and/or immunosuppressive or immunomodulatory therapy $[1,2]$. The respective frequency of manifestations, their clinical and radiological presentations, response to treatment, and outcome are dependent on the underlying CTD.

Rheumatoid arthritis may be responsible for a broad spectrum of manifestations, including: pleural effusion; chronic interstitial pneumonia; lung rheumatoid nodules; bronchiectasis; obstructive ventilatory defect due to constrictive bronchiolitis; laryngeal involvement; and opportunistic infections, such as mycobacterial infections facilitated by anti-tumour necrosis factor- $\alpha$ treatments. Systemic sclerosis may be commonly associated with chronic interstitial pneumonia (especially in patients with diffuse systemic sclerosis and antitopoisomerase-1 antibodies), or pulmonary arterial hypertension (most frequently, but not exclusively, in patients with limited systemic sclerosis with anti-centromere antibodies), with both contributing to the unfavourable prognosis of the disease [3].

Although less frequent among CTDs than rheumatoid arthritis and systemic sclerosis, the spectrum of idiopathic inflammatory myopathy (including dermatomyositis, polymyositis, and amyopathic dermatomyositis) may give rise to a variety of respiratory manifestations, which represent a common cause of death in these patients. These include interstitial lung disease (ILD), aspiration pneumonia, ventilatory failure secondary to diaphragmatic dysfunction [4], and rarely, acute respiratory distress syndrome, pleural effusion, pneumothorax, pulmonary hypertension [5], diffuse alveolar haemorrhage, and dyspnoea due to dermatopolymyositisrelated cardiac disease $[2,6]$. In addition, some manifestations may be the consequence of treatment, such as drug-induced pneumonitis and opportunistic infections. First described in 1986 [7], the high frequency of pneumomediastinum in dermatomyositis has been better appreciated more recently [8].

CORRESPONDENCE: V. Cottin, Hospices Civils de Lyon, Hôpital Louis Pradel, Université Lyon 1, 28 avenue Lépine, 69677 Lyon (Bron) Cedex, France. Fax: 33 472357653. E-mail: vincent.cottin@chuIyon.fr
The association of ILD and dermatomyositis, described in 1956 [9], is now recognised as a direct complication of CTD and carries a poor outcome [10]. ILD occurs in $5-30 \%$ of patients with dermatomyositis [2], with prevalence depending on whether chest radiographs, lung function tests or highresolution computed tomography of the chest are used for screening. In a recent retrospective study, diffuse parenchymal lung disease diagnosed by chest radiograph was present in 70 (7.2\%) out of 973 patients [11]. The presence of anti-tRNAsynthetase antibodies, including anti-Jo-1 antibodies, has been reported as a marker of a subset of patients with dermatomyositis who have an increased risk of developing ILD [1215].

Although several histopathological patterns have been described in patients with idiopathic inflammatory myopathyassociated ILD, including organising pneumonia, usual interstitial pneumonia (UIP), organising diffuse alveolar damage and lymphocytic interstitial pneumonia [11, 15-21], nonspecific interstitial pneumonia (NSIP) is the most frequent histopathological pattern [11, 20, 22]. Idiopathic NSIP has been demonstrated to have a better prognosis than idiopathic pulmonary fibrosis (IPF) [23]. Due to the high frequency of NSIP, survival of patients with dermatomyositis-related ILD is also better than that of IPF [11]. NSIP is also the most frequent pattern of ILD in systemic sclerosis [24] and primary Sjögren's syndrome [25], whereas UIP may be more frequent in rheumatoid arthritis [26].

Despite the fact that ILD associated with inflammatory myopathy and other CTDs has been well identified, we may still be missing some forms of CTD-related ILD while in the process of investigating the diagnosis of ILD, for several reasons. First, the ILD may precede the diagnosis of CTD, the manifestations of which being moderate or overlooked, so that the ILD may not be ascribed to CTD from the start. In some cases, the ILD may actually precede any systemic manifestation of the CTD, which may follow by several months or years, then correcting the diagnosis of what had been hitherto considered as idiopathic NSIP or IPF. This has been described in as many as $20 \%$ of patients with idiopathic inflammatory myopathy [20, 27], as well as $17 \%$ of patients with rheumatoid arthritis [26].

Secondly, CTD may be limited to "formes frustes", which may be particularly difficult to recognise. Classification criteria for systemic sclerosis now include systemic sclerosis sine scleroderma, a condition characterised by the involvement of visceral organs (lungs, kidneys, gastrointestinal system), 
abnormal nailfold capillaries and antinuclear antibodies, but with minimal or no cutaneous involvement [28, 29], which may be associated with progressive ILD [30]. Similarly, a subset of patients with idiopathic inflammatory myopathy may have dissociated skin and skeletal muscle involvement, and patients may have florid cutaneous manifestations of dermatomyositis for a prolonged period of time (at least 2 yrs according to the definition [31]) without any evidence of underlying myositis. This condition has been termed amyopathic dermatomyositis (or dermatomyositis sine myositis), and has been included in the clinical spectrum of idiopathic inflammatory myopathy [31-33]. Most patients with amyopathic dermatomyositis have no objective evidence of myopathy and do not progress to the full syndrome of dermatomyositis. Conversely, some patients may have mildly elevated muscle enzymes or abnormalities of electromyogram, magnetic resonance imaging of the muscles, or of the muscle biopsy when performed (mild infiltration with inflammatory cells, with no evidence of muscle fibre necrosis) [34], a condition sometimes referred to as hypomyopathic dermatomyositis. It has recently been shown that ILD, and especially NSIP, may be associated with and may antedate amyopathic dermatomyositis [20]. Thus, particular attention should be paid to cutaneous changes in a patient with ILD, such as heliotrope rash, facial erythema and oedema, Gottron's papules, and periungual telangiectasia, especially if the histopathological pattern is NSIP [35].

Thirdly, the recognition of the underlying CTD may be even more difficult when the onset of the disease is acute or subacute, a condition which has been occasionally reported in patients with dermatomyositis $[19,21]$. In this regard, in the current issue of the European Respiratory Journal, SuDA et al. [36] have addressed novel aspects of the clinical presentation of ILD in dermatomyositis. Hence, in a retrospective cohort of 14 patients with amyopathic dermatomyositis, they identified two distinct profiles according to the clinical onset. While five out of 12 patients had a chronic ILD with a slowly progressive deterioration (often with a histopathological pattern of NSIP when lung biopsy was performed), the majority of patients (seven out of 12) presented with a subacute or acute diffuse lung disease, with a pattern of diffuse alveolar damage on histopathology. Consolidation (associated with ground-glass opacities) was more common in patients with acute/subacute ILD. Response to treatment and outcome were much better in the chronic than in the acute/subacute form of the disease.

The limitations of the study by SUDA et al. [36] include its retrospective design and small size. Although most patients had a clinical and radiological pattern that differs from IPF, only a minority underwent a lung biopsy (mostly due to the rapid onset of the lung disease). Biological investigations were not extensive despite the surprisingly low prevalence of antiJo-1 antibodies (myositis-associated antibodies other than antiJo-1 antibodies were not measured). Surprisingly, the lung disease never preceded the cutaneous manifestations, contrasting with previous observations [20, 27].

Acute respiratory deteriorations of ILD have occasionally been reported in patients with idiopathic inflammatory myopathy $[11,19,37]$, as well as rheumatoid arthritis, systemic lupus erythematosus and systemic sclerosis [2, 38], and are usually associated with a poor prognosis. Acute/subacute forms of
CTD-associated ILD share the features of acute exacerbations of IPF, a condition also characterised by recent onset of increased dyspnoea, diffuse bilateral ground-glass opacities superimposed on subpleural reticular and honeycombing densities, and worsening gas exchange, in the absence of an identifiable cause other than the pre-existing ILD. Diffuse alveolar damage superimposed on pre-existing UIP is the pattern found on histopathology [39-41].

Whether or not the current classification of idiopathic interstitial pneumonia [42] (mostly based on histopathology) adequately applies to ILD associated with CTD is still debatable. For example, it has been shown that the prognostic significance of the histopathological pattern of lung disease related to systemic sclerosis (NSIP versus UIP) differs from that of the idiopathic counterpart of these entities [24]. Fewer fibroblastic foci were found in patients with UIP in the context of CTD than in those with IPF $[43,44]$, suggesting that these entities may be distinct. The study by SuDA et al. [36] tends to indicate that some cases of ILD (especially with an acute onset), occurring in the context of idiopathic inflammatory myopathy or formes frustes of CTD, may include features from several of the corresponding clinicopathological idiopathic entities of the classification (namely NSIP and diffuse alveolar damage), but do not fit well into a single one of them.

Are will still missing some cases of formes frustes of CTD, and why is a precise diagnosis so important in ILD? One might argue that idiopathic and CTD-related ILD often end up with undifferentiated treatments, such as corticosteroids and immunosuppressive therapy. However, in recent years, better delineation of the diagnosis of IPF has been followed by better evidence that "conventional" treatment is ineffective in this disease, and has opened the path to prospective therapeutic trials, which may ultimately lead to effective treatments of this devastating disease. Similarly, there has been some hope that early therapeutic intervention may be beneficial in patients with (idiopathic) acute interstitial pneumonia [45]. Hopefully, progress in our understanding of CTD-related ILD will also provide new treatment perspectives in the future, as recently suggested in systemic sclerosis [46].

The discovery of myositis-associated antibodies (including those specific for aminoacyl-transfer RNA synthetase, antisignal recognition particle, and anti-Mi-2 antibodies) has led to a serological approach that is complementary to the clinical evaluation [47]. The recent identification of antibodies that may be specifically associated with amyopathic dermatomyositis (C-ADM-140 antibodies, representing clinically amyopathic dermatomyositis, autoantigen of $140 \mathrm{kDa}$ ) might aid an earlier diagnosis of this condition, especially in acute or inaugural interstitial pneumonia [48]. Similarly, nucleolar-staining antinuclear antibodies with $\mathrm{Th} / \mathrm{To}$ specificity may help to differentiate patients with systemic sclerosis sine scleroderma from those with idiopathic pulmonary fibrosis [49]. Thus, it is anticipated that in the near future, identification of novel biological markers may help us to better delineate idiopathic interstitial lung disease from formes frustes of connective tissue disease. As for now, careful evaluation of patients with interstitial lung disease remains the mainstay of the diagnostic process. 


\section{ACKNOWLEDGEMENTS}

The author would like to thank J.F. Cordier for his helpful suggestions in the preparation of this manuscript.

\section{REFERENCES}

1 Crestani B. The respiratory system in connective tissue disorders. Allergy 2005; 60: 715-734.

2 Freemer MM, King TE Jr. Connective tissue diseases. In: Schwarz MI, King TE Jr, eds. Interstitial Lung Disease. 4th Edn. Hamilton, B.C. Decker Inc, 2003; pp. 535-598.

3 Ferri C, Valentini G, Cozzi F, et al. Systemic sclerosis: demographic, clinical, and serologic features and survival in 1,012 Italian patients. Medicine (Baltimore) 2002; 81: 139-153.

4 Teixeira A, Cherin P, Demoule A, et al. Diaphragmatic dysfunction in patients with idiopathic inflammatory myopathies. Neuromuscul Disord 2005; 15: 32-39.

5 Handa T, Nagai S, Kawabata D, et al. Long-term clinical course of a patient with anti PL-12 antibody accompanied by interstitial pneumonia and severe pulmonary hypertension. Intern Med 2005; 44: 319-325.

6 Baumann $\mathrm{MH}$. The lung in polymyositis and dermatomyositis. Semin Respir Crit Care Med 1999; 20: 131-138.

7 Bradley JD. Spontaneous pneumomediastinum in adult dermatomyositis. Ann Rheum Dis 1986; 45: 780-782.

8 de Souza Neves F, Shinjo SK, Carvalho JF, Levy-Neto M, Borges CT. Spontaneous pneumomediastinum and dermatomyositis may be a not so rare association: report of a case and review of the literature. Clin Rheumatol 2006; [Epub ahead of print PMID: 16622592].

9 Mills ES, Matthews WH. Interstitial pneumonitis in dermatomyositis. JAMA 1956; 160: 1467-1470.

10 Marie I, Hachulla E, Hatron PY, et al. Polymyositis and dermatomyositis: short term and long term outcome, and predictive factors of prognosis. J Rheumatol 2001; 28: 2230-2237.

11 Douglas WW, Tazelaar HD, Hartman TE, et al. Polymyositis-dermatomyositis-associated interstitial lung disease. Am J Respir Crit Care Med 2001; 164: 1182-1185.

12 Hochberg MC, Feldman D, Stevens MB, Arnett FC, Reichlin M. Antibody to Jo-1 in polymyositis/dermatomyositis: association with interstitial pulmonary disease. $J$ Rheumatol 1984; 11: 663-665.

13 Love LA, Leff RL, Fraser DD, et al. A new approach to the classification of idiopathic inflammatory myopathy: myositis-specific autoantibodies define useful homogenous patient groups. Medicine (Baltimore) 1991; 70: 360-374.

14 Yoshida S, Akizuki M, Mimori T, Yamagata H, Inada S, Homma $\mathrm{M}$. The precipitating antibody to an acidic nuclear protein antigen, the Jo- 1 , in connective tissue diseases. A marker for a subset of polymyositis with interstitial pulmonary fibrosis. Arthritis Rheum 1983; 26: 604-611.

15 Marie I, Hachulla E, Cherin P, et al. Interstitial lung disease in polymyositis and dermatomyositis. Arthritis Rheum 2002; 47: 614-622.

16 Dickey BF, Myers AR. Pulmonary disease in polymyositis / dermatomyositis. Semin Arthritis Rheum 1984; 14: 60-76.

17 Duncan PE, Griffin JP, Garcia A, Kaplan SB. Fibrosing alveolitis in polymyositis. A review of histologically confirmed cases. Am J Med 1974; 57: 621-626.
18 Schwarz MI, Matthay RA, Sahn SA, Stanford RE, Marmorstein BL, Scheinhorn DJ. Interstitial lung disease in polymyositis and dermatomyositis: analysis of six cases and review of the literature. Medicine (Baltimore) 1976; 55: 89-104.

19 Tazelaar HD, Viggiano RW, Pickersgill J, Colby TV. Interstitial lung disease in polymyositis and dermatomyositis. Clinical features and prognosis as correlated with histologic findings. Am Rev Respir Dis 1990; 141: 727-733.

20 Cottin V, Thivolet-Bejui F, Reynaud-Gaubert M, et al. Interstitial lung disease in amyopathic dermatomyositis, dermatomyositis and polymyositis. Eur Respir J 2003; 22: 245-250.

21 Lee CS, Chen TL, Tzen CY, et al. Idiopathic inflammatory myopathy with diffuse alveolar damage. Clin Rheumatol 2002; 21: 391-396.

22 Arakawa H, Yamada H, Kurihara Y, et al. Nonspecific interstitial pneumonia associated with polymyositis and dermatomyositis: serial high-resolution $\mathrm{CT}$ findings and functional correlation. Chest 2003; 123: 1096-1103.

23 Bjoraker JA, Ryu JH, Edwin MK, et al. Prognostic significance of histopathologic subsets in idiopathic pulmonary fibrosis. Am J Respir Crit Care Med 1998; 157: 199-203.

24 Bouros D, Wells AU, Nicholson AG, et al. Histopathologic subsets of fibrosing alveolitis in patients with systemic sclerosis and their relationship to outcome. Am J Respir Crit Care Med 2002; 165: 1581-1586.

25 Ito I, Nagai S, Kitaichi M, et al. Pulmonary manifestations of primary Sjogren's syndrome: a clinical, radiologic and pathologic study. Am J Respir Crit Care Med 2005; 171: 632-638.

26 Lee HK, Kim DS, Yoo B, et al. Histopathologic pattern and clinical features of rheumatoid arthritis-associated interstitial lung disease. Chest 2005; 127: 2019-2027.

27 Marie I, Hatron PY, Hachulla E, Wallaert B, MichonPasturel U, Devulder B. Pulmonary involvement in polymyositis and in dermatomyositis. J Rheumatol 1998; 25: 1336-1343.

28 Rodnan GP, Fennell RH Jr. Progressive systemic sclerosis sine scleroderma. JAMA 1962; 180: 665-670.

29 Poormoghim H, Lucas M, Fertig N, Medsger TA Jr. Systemic sclerosis sine scleroderma: demographic, clinical, and serologic features and survival in forty-eight patients. Arthritis Rheum 2000; 43: 444-451.

30 Lomeo RM, Cornella RJ, Schabel SI, Silver RM. Progressive systemic sclerosis sine scleroderma presenting as pulmonary interstitial fibrosis. Am J Med 1989; 87: 525-527.

31 Sontheimer RD. Would a new name hasten the acceptance of amyopathic dermatomyositis (dermatomyositis sine myositis) as a distinctive subset within the idiopathic inflammatory dermatomyopathies spectrum of clinical illness? J Am Acad Dermatol 2002; 46: 626-636.

32 Euwer RL, Sontheimer RD. Amyopathic dermatomyositis (dermatomyositis sine myositis). Presentation of six new cases and review of the literature. J Am Acad Dermatol 1991; 24: 959-966.

33 Euwer RL, Sontheimer RD. Amyopathic dermatomyositis: a review. J Invest Dermatol 1993; 100: 124S-127S. 
34 el-Azhary RA, Pakzad SY. Amyopathic dermatomyositis: retrospective review of 37 cases. J Am Acad Dermatol 2002; 46: 560-565.

35 Cottin V, Donsbeck AV, Revel D, Loire R, Cordier JF. Nonspecific interstitial pneumonia. Individualization of a clinicopathologic entity in a series of 12 patients. Am J Respir Crit Care Med 1998; 158: 1286-1293.

36 Suda T, Fujisawa T, Enomoto N, et al. Interstitial lung diseases associated with amyopathic dermatomyositis. Eur Respir J 2006; 28: 1005-1012.

37 Selva-O'Callaghan A, Labrador-Horrillo M, Munoz-Gall X, et al. Polymyositis/dermatomyositis-associated lung disease: analysis of a series of 81 patients. Lupus 2005; 14: 534-542.

38 Muir TE, Tazelaar HD, Colby TV, Myers JL. Organizing diffuse alveolar damage associated with progressive systemic sclerosis. Mayo Clin Proc 1997; 72: 639-642.

39 Ambrosini V, Cancellieri A, Chilosi M, et al. Acute exacerbation of idiopathic pulmonary fibrosis: report of a series. Eur Respir J 2003; 22: 821-826.

40 Kim DS, Park JH, Park BK, Lee JS, Nicholson AG, Colby T. Acute exacerbation of idiopathic pulmonary fibrosis: frequency and clinical features. Eur Respir J 2006; 27: 143-150.

41 Martinez FJ, Safrin S, Weycker D, et al. The clinical course of patients with idiopathic pulmonary fibrosis. Ann Intern Med 2005; 142: 963-967.

42 American Thoracic Society, European Respiratory Society. American Thoracic Society/European Respiratory Society
International Multidisciplinary Consensus Classification of the Idiopathic Interstitial Pneumonias. Am J Respir Crit Care Med 2002; 165: 277-304.

43 Flaherty KR, Colby TV, Travis WD, et al. Fibroblastic foci in usual interstitial pneumonia: idiopathic versus collagen vascular disease. Am J Respir Crit Care Med 2003; 167: 1410-1415.

44 Enomoto N, Suda T, Kato M, et al. Quantitative analysis of fibroblastic foci in usual interstitial pneumonia. Chest 2006; 130: 22-29.

45 Suh GY, Kang EH, Chung MP, et al. Early intervention can improve clinical outcome of acute interstitial pneumonia. Chest 2006; 129: 753-761.

46 Tashkin DP, Elashoff R, Clements PJ, et al. Cyclophosphamide versus placebo in scleroderma lung disease. N Engl J Med 2006; 354: 2655-2666.

47 Troyanov Y, Targoff IN, Tremblay JL, Goulet JR, Raymond Y, Senecal JL. Novel classification of idiopathic inflammatory myopathies based on overlap syndrome features and autoantibodies: analysis of 100 French Canadian patients. Medicine (Baltimore) 2005; 84: 231-249.

48 Sato S, Hirakata M, Kuwana M, et al. Autoantibodies to a 140-kd polypeptide, CADM-140, in Japanese patients with clinically amyopathic dermatomyositis. Arthritis Rheum 2005; 52: 1571-1576.

49 Fischer A, Pfalzgraf FJ, Feghali-Bostwick CA, et al. AntiTh/To-Positivity in a cohort of patients with idiopathic pulmonary fibrosis. J Rheumatol 2006; 33: 1600-1605. 